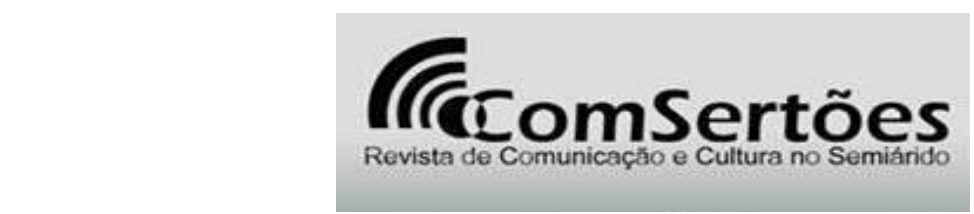

\title{
PROJETOS, OFICINAS E PRÁTICAS DE LETRAMENTO: LEITURA E AÇÃO SOCIAL
}

\author{
Ivoneide B. A. Santos Marques ${ }^{1}$ \\ Angela Bustos Kleiman ${ }^{2}$
}

\section{Resumo}

Este artigo tem por objetivo apresentar uma análise crítico-reflexiva de uma oficina de leitura no âmbito de um projeto de letramento, realizada no segundo ano do Ensino Médio (EM), em uma escola de Natal-RN. O estudo, desenvolvido em uma abordagem qualitativa e interpretativista, funda-se em uma concepção sócio-histórica de linguagem, nos Estudos do letramento e na Nova Retórica. Os resultados apontam que, pelo seu caráter pedagógico, dinâmico, prático, dialógico e participativo, as oficinas de letramento motivam os alunos à aprendizagem e contribuem para ampliar os seus letramentos, preparando-os para o exercício da cidadania crítica e participativa, ao enraizá-los no contexto sócio-histórico.

Palavras-chave: Letramento crítico. Projeto de letramento. Oficina de letramento. Práticas de letramento. Ensino de leitura. Gênero discursivo.

\section{LITERACY PROJECTS, WORKSHOPS AND PRACTICES: READING AND SOCIAL ACTION}

\begin{abstract}
The purpose of this study is to analyze critically a reading workshop developed in order to implement a literacy project carried out by second year high school students in a school situated in the city of Natal in Rio Grande do Norte. This study, qualitative and interpretative in nature, is based on the Bakhtinian socio-historical

\footnotetext{
${ }^{1}$ Professora do Instituto Federal de Educação, Ciência e Tecnologia do Rio Grande do Norte (IFRN), doutora em Estudos da Linguagem pela Universidade Federal do Rio Grande do Norte (UFRN), onde atua como docente no Programa de Pós-graduação em Estudos da Linguagem. Atualmente, está vinculada à UNICAMP como pesquisadora colaboradora, desenvolvendo pesquisa de pós-doutorado sob a orientação da professora Angela B. Kleiman.

${ }^{2}$ Professora Titular aposentada, colaboradora voluntária no Programa de Pós-graduação em Linguística Aplicada do Instituto de Estudos da linguagem da UNICAMP. Bolsista de Produtividade em Pesquisa do CNPq, nível 1-A.
} 
language conception, on the New Literacy Studies (Estudos do Letramento in Brazil) and on the New Rhetoric Studies. Our results indicate that, due to their pedagogic, dynamic, dialogic and participative character, literacy workshops motivate student learning and contribute to increase the students' literacies, thus preparing them for the exercise of participative citizenship practices and enhancing their understanding of their socio-historical context.

Keywords: Critical Literacy. Literacy Project. Literacy workshop. Literacy practices. Teaching of Reading. Discourse genre.

\section{PROYECTOS, TALLERES Y PRÁCTICAS DE LITERACIDAD: LECTURA Y ACCIÓN SOCIAL}

\section{Resumen}

El objetivo de este artículo es analizar críticamente un taller de lectura desarrollado como parte de la implementación de un proyecto de literacidad realizado por alumnos del segundo año del secundario en una escuela localizada en la ciudad de Natal, en Rio Grande do Norte. Este trabajo, de naturaleza interpretativa y cualitativa, está basado en la concepción socio-histórica de lenguaje del Círculo de Bakhtin, en los Estudios de Literacidad y en los Estudios de la Nueva Retórica. Los resultados de la investigación sugieren que, debido a sus características pedagógicas dinámicas, dialógicas y participativas, los talleres de lectura favorecen el aprendizaje de los alumnos y contribuyen para el aumento de sus prácticas de literacidad, lo que los prepara para el ejercicio de participación en prácticas ciudadanas e intensifica su comprensión del contexto socio-histórico en que viven.

Palabras clave: Literacidad crítica. Proyecto de literacidad. Taller de literacidad. Prácticas de literacidad. Enseñanza de lectura. Género discursivo.

A nação não sabe ler. Há só 30\% dos indivíduos residentes neste país que podem ler; destes uns $9 \%$ não lêem letra de mão. $70 \%$ jazem em profunda ignorância. (...). $70 \%$ dos cidadãos votam do mesmo modo que respiram: sem saber por que nem o quê. Votam como vão à festa da Penha por divertimento. A Constituição é para eles uma coisa inteiramente desconhecida. As instituições existem, mas por e para $30 \%$ dos cidadãos.

(Machado de Assis - Correspondência, [1879] 1937)

\section{Introdução}

A problemática das dificuldades de leitura do povo brasileiro não é recente e o impacto negativo disso na vivência da cidadania plena, especialmente nas classes sociais menos favorecidas, é uma realidade. Como já denunciava o escritor Machado de 
Assis em sua obra Correspondência no Século XIX, as questões de leitura não podem ser dissociadas das questões de cidadania. O autor afirma que "Há só $30 \%$ dos indivíduos residentes neste país que podem ler". Assim como era ontem, ainda hoje, nem todos têm assegurado o direito à educação.

Enquanto o acesso à leitura ainda não for democratizado, a cidadania será um privilégio de poucos: ser cidadão demanda a compreensão crítica da realidade e a assunção de posicionamentos diante dela, vislumbrando transformá-la, e, com o avanço e o predomínio da escrita em praticamente todas as esferas da vida, precisamos ser leitores proficientes para compreendermos a realidade. Contudo, nem todos estão alfabetizados ainda e, daqueles que já estão, muitos têm dificuldade para extrair informações, fazer inferências e comparações, tirar conclusões com base na leitura.

Um ponto que tem sido negligenciado na escola, apesar das recomendações de documentos reguladores do ensino, diz respeito às organizações e dispositivos didáticos para subsidiar pedagogicamente o trabalho do professor, como os projetos educacionais que, embora recomendados por esses documentos para fundar didaticamente a atividade pedagógica, continuam a ser algo incomum na rotina de professores e alunos do ensino médio. Aqui, propomo-nos tratar mais especificamente de oficinas de leitura desenvolvidas num projeto de letramento.

Observamos que a escola ainda não incorporou de forma mais efetiva o trabalho com projetos no seu cotidiano, embora isso pudesse impulsionar o desenvolvimento de práticas pedagógicas baseadas na interligação de saberes de diversos componentes curriculares, o que seria importante para colocar a leitura como um eixo articulador de diferentes conteúdos disciplinares. Não queremos com isso dizer que todos os projetos aglutinem a todo custo todas as disciplinas, pois a imposição disso contribuiria para artificializar as práticas de letramento e inviabilizar os projetos em escolas em que há, por exemplo, um ou dois docentes interessados em efetivá-los. Significamos que, na medida do possível, um mesmo objeto seja investigado em diversas áreas do conhecimento, atendendo às orientações dos Parâmetros Curriculares Nacionais do Ensino Médio (PCNEM), dessa forma investindo em estratégias de superação da fragmentação do ensino.

Essa fragmentação, também presente no ensino de leitura e escrita, pode ser superada a partir dos chamados projetos de letramento, baseados na "leitura de textos que, de fato, circulam na sociedade" (KLEIMAN, 2000, p.238). Esses projetos podem 
ser considerados como uma alternativa didática para redimensionar o modelo tradicional de ensino e sua forma bancária de ensinar, em que se abstrai a problematização da prática pedagógica, desconsiderando a realidade social do aluno (FREIRE, 1978), pois nesses projetos possibilita-se que objetivos e objetos de ensino da língua sejam ressignificados em uma perspectiva de ensino crítica e dialógica.

Considerando o potencial inovador desse tipo de projeto, neste artigo, temos por objetivo apresentar uma análise de uma oficina de leitura, realizada no âmbito de um projeto de letramento utilizado como organização didática para o desenvolvimento da competência leitora e escritora dos alunos de duas turmas do segundo ano do Ensino Médio (EM) de uma escola de Natal - RN. Ressaltamos que, embora nesse tipo de projeto as práticas de leitura e escrita se desenvolvam de forma imbricada, neste trabalho, destacaremos o trabalho realizado em oficinas de leitura que integraram as atividades do projeto de letramento "Desarmar o Brasil: por uma cultura de paz", realizado em 2005, porém de alta relevância e atualidade hoje, quase quinze anos depois.

O texto está dividido nas seguintes seções, além desta introdução: na primeira, situamos a problemática objeto de nossa reflexão e a questão da necessidade de ressignificação das práticas de letramento desenvolvidas no ensino médio em contexto escolar; na segunda, apresentamos o quadro referencial teórico em que se ancora a discussão; na terceira, apresentamos o projeto de letramento para melhor situar o leitor sobre como se configura um projeto dessa natureza; na quarta, analisamos as oficinas de leitura de charges e, na quinta seção, tecemos considerações finais sobre a discussão desenvolvida neste estudo.

\section{Argumentos para uma relação entre projetos de letramento e cidadania}

A forma como a leitura e a escrita são conduzidas, em muitas instituições de ensino médio, pouco contribui para uma educação com autonomia que permita desenvolver atividades que correlacionem a teoria e a prática, a escola e o cotidiano dos alunos, as práticas escolarizadas e as práticas letradas vivenciadas em outras esferas sociais, além da escola. 
Um ensino da leitura que se encaixe em uma perspectiva contextualizada impõenos a necessidade de um suporte teórico que permita ampliar a visão sistêmica que se tem da língua. A concepção de linguagem assumida pelo professor para orientar o trabalho na escola não se reduz a uma opção teórica. Ela o orienta sobre o que, para que e como ensinar. Nesse sentido, este estudo está ancorado na concepção de linguagem de base bakhtiniana em cuja essência a língua é entendida como ação social e a linguagem como produto histórico e social, que tem no dialogismo o seu princípio fundador (VOLOCHINOV, $2000^{3}$ ).

Vinculada a essa concepção de linguagem consideramos também a noção de gênero discursivo construído num viés sócio-histórico, cujo domínio permite a participação em diversas situações que demandem os usos da linguagem (BAKHTIN, $\left.1999^{4}\right)$. Ao conceito de gênero discursivo aqui apresentado, acrescentamos também a noção de ação social proposta pelo grupo da Nova Retórica (MILLER, 2009, BAZERMAN, 2005; 2006), que complementa essa concepção bakhtiniana. Esta teoria considera o caráter dinâmico, interativo e agentivo do uso dos gêneros, visto que se torna bastante relevante, neste estudo, a concepção de estudantes como agentes de letramento (KLEIMAN, 2006), capazes de perceber na escrita uma poderosa ferramenta para realizar coisas e marcar presença no mundo.

Os estudos do letramento são relevantes em razão de abrirem novas perspectivas para uma reflexão crítica sobre as práticas letradas propostas pela escola, por considerarem a escrita em uma perspectiva situada, definindo o letramento como "um conjunto de práticas sociais cujos modos específicos de funcionamento têm implicações importantes para as formas pelas quais os sujeitos envolvidos nessas práticas constroem relações de identidade e poder" (KLEIMAN,1995, p. 11).

Sob a ótica dos estudos de letramento, a escrita pode ser vista como instrumento de poder e inclusão social. Ao atribuir novos sentidos ao ler e ao escrever, a escola assume um maior engajamento na produção de práticas emancipatórias, oferecendo ao aluno possibilidades de compreensão e intervenção na sua realidade social e pessoal. A imersão dos sujeitos em práticas situadas pode levá-los a discursos institucionais mais amplos, interferindo nas suas ações e atitudes. Eles rompem fronteiras e migram de um espaço micro para um macro, entretecendo fios discursivos distintos, sendo, por isso,

\footnotetext{
${ }^{3}$ Publicação original de 1929.

${ }^{4}$ A data da publicação original é 1945.
} 
importante considerar o que dizem e fazem com os textos que produzem (BARTON; HAMILTON \& IVANIC, 2000).

Dos estudos de letramento, destacamos o conceito de projetos de letramento de Kleiman (2000). Os projetos de letramento podem se tornar importantes instrumentos na dinamização dos processo de ensino e aprendizagem da leitura e da escrita, conforme apontam algumas experiências exitosas advindas do trabalho realizado com eles ${ }^{5}$. Leitura e escrita, entendidas como práticas sociais, tornam-se movimentos complementares e não atividades que se encerram em si mesmas. Aprender a escrever presume uma formação leitora do escrevente. $\mathrm{O}$ amadurecimento da produção escrita está intimamente ligado ao desenvolvimento da competência leitora dos estudantes que veem a língua funcionar com os efeitos de sentido produzidos nas diversas versões de um mesmo texto.

No trabalho com a língua escrita, a leitura assume o caráter de prática social ${ }^{6}$ de alcance político, quando desenvolvida em uma proposta educativa baseada no diálogo. "Uma educação dialogal e ativa, voltada para a responsabilidade social e política se caracteriza pela profundidade na interpretação dos problemas" (FREIRE, 1971, p. 69). Nesse sentido, as práticas de leitura crítica visam oferecer ao aluno as condições para a apreensão da sua realidade social.

Nos projetos de letramento, a aprendizagem das práticas de linguagem tem maiores chances de êxito por se tornarem significativas para os alunos e, nesse processo, se tornarem críticas pelo potencial fortalecedor que adquirem, favorecendo a agência cívica e a participação social. Nesse tipo de projeto, os estudantes desenvolvem maior conscientização quando aprendem a agir socialmente. É pelo ativismo entendido como uma forma de argumentar não apenas especulativa mas que favorece a prática efetiva de transformação da realidade - que os estudantes percebem como a leitura é instrumento essencial para a construção da cidadania.

\footnotetext{
${ }^{5}$ Entre os estudos que tematizam o trabalho com as práticas de letramento no contexto escolar podemos mencionar ANASTÁCIO; GARCIA (2014); CORREIA (2016); CUNHA (2010); DIAS (2016); FREIRE (2017); KLEIMAN (2009); OLIVEIRA (2008; 2016); SANTOS (2008; 2012); SANTOS MARQUES (2016; 2016a); KLEIMAN; CENICEROS; TINOCO (2013); e, com foco mais voltado para o contexto da academia em processos de formação inicial ou continuada de professores, temos TINOCO (2008) SANTOS MARQUES (2016a).

${ }^{6}$ Baseando-nos em Scribner \& Cole (1981), a noção de prática social é aqui compreendida como uma sequência de atividades que dependem de tecnologias, saberes e capacidades para agir e mobilizar recursos numa dada situação de comunição.
} 
A formação crítica para a cidadania não se coaduna com o modelo de formação neoliberal, ancorado em um exagerado pragmatismo que limita a prática pedagógica ao treinamento técnico e científico dos educandos, em detrimento de uma formação técnica e científica essencial, nunca limitada a treinamento. Ensinar a ler, tomando por base esses pressupostos, torna-se desafiador e implica a assunção de uma concepção de educação que considere que a formação de pessoas críticas, curiosas, indagadoras e capazes de raciocinar rapidamente "não pode ser a que exercita a memorização mecânica [...] a que treina em lugar de formar" (FREIRE, 2000, p. 115).

Os projetos de letramento podem implementar mudanças necessárias ao trabalho com práticas discursivas voltadas para a participação social crítica, pois desenvolvem, nos sujeitos, um espírito de cooperação e co-responsabilidade em relação àquilo que realizam, promovendo a aprendizagem e o desenvolvimento de sua auto-estima e autoconfiança. Esses projetos viabilizam a ressignificação das práticas letradas desenvolvidas na escola, contribuindo para que haja um maior e mais profundo diálogo entre a escola e outras instituições, a escola e outras esferas de atividade.

A aprendizagem se dá vivencialmente, isto é, o modo situado: o que os alunos aprendem tem um relevante papel no conhecimento que querem construir. Nessa perspectiva situada de cognição, coletivamente, as atividades se tornam mais autênticas para os alunos, favorecendo as habilidades de pensamento e de resolução de problemas dentro e fora da escola.

\section{O projeto: "Desarmar o Brasil: por uma cultura de paz"}

Nesta seção, descrevemos o modo de desenvolvimento de um projeto de letramento, cujo objetivo era ampliar a competência leitora e escritora de alunos de duas turmas do segundo ano do $\mathrm{EM}^{7}$ de uma escola de Natal - RN. Na experiência, contamos com a participação de oitenta e cinco alunos, matriculados em duas turmas do segundo ano do ensino médio, de faixa etária que variava entre 16 e 18 anos de idade.

Os dados foram gerados no ano de 2005, durante um trimestre, em quarenta aulas de cinquenta minutos cada uma. Constam de registros de eventos de letramento

\footnotetext{
${ }^{7}$ A título de ilustração, outras experiências exitosas com projetos de letramento no EM regular podem ser mencionadas (SANTOS, 2008; CUNHA, 2010) e também na modalidade EJA e na Educação Profissional integrada à EJA (SANTOS, 2012; SANTOS MARQUES; KLEIMAN, 2017).
} 
em que foram trabalhados diversos gêneros discursivos (debate regrado, reportagem, editorial, artigo de opinião. carta aberta, faixa, cartaz, charge, notícia, Lei etc.) em diferentes práticas de leitura (e de escrita com o propósito de circulação social), resultando em publicações de carta aberta, cartas do leitor, comentários no site do colégio e em um dos principais jornais da cidade, a Tribuna do Norte.

Em um projeto de letramento, o tema é definido coletivamente com os alunos e emerge de suas necessidades e interesses. Assim, tem sido comum o trabalho com temas que estão na ordem do dia, isto é, temas atuais e, muito frequentemente, polêmicos, o que, além de facilitar a construção de repertórios, favorece a formação crítica e o trabalho com os textos argumentativos, essencial à formação cidadã dos educandos. $\mathrm{O}$ acesso aos recursos e materiais de leitura se torna mais fácil, já que o tema está em plena efervecência circulando em diferentes gêneros (notícias, charges, editoriais, reportagens, cartas do leitor, comentários etc.) e diferentes mídias (vídeos, áudios, documentários, filmes, livros etc.), em diversos espaços de circulação de textos (redes sociais, sites, jornais e revistas impressas ou digitais) e em diversas modalidades, incluindo gêneros orais do cotidiano.

A atualidade de uma temática a ser investigada tem grande relevância no desenvolvimento de um projeto de letramento, pois assim, imprime-se dinamicidade ao processo de ensino: tema e problema precisam estar vinculados à ideia de cotidiano no seu sentido plural: o cotidiano da comunidade, da escola e do aluno (SANTOS; OLIVEIRA, 2012, p. 49).

No projeto em estudo, o tema do desarmento foi escolhido pelos alunos por estar em ampla discussão na sociedade brasileira naquele ano, quando estava em processo a realização de um referendo ${ }^{8}$ popular no Brasil, que ocorreu em 23 de outubro de 2005 e teve como objeto de discussão a proibição da comercialização de armas de fogo e munições, partindo da seguinte questão exposta à consulta popular: o comércio de armas de fogo e munição deve ser proibido no Brasil? O referendo já estava previsto no projeto de desenvolvimento da Lei 10826 de 22 de dezembro de 2003, que trata do Estatuto do Desarmamento, o qual previa também "art. 35 - É proibida a

\footnotetext{
${ }^{8}$ Referendo diz respeito a normas legais ou constitucionais. Como instrumento de participação direta, é um modo de expressão da vontade e da opinião dos cidadãos a partir do voto livre e secreto, para decidir sobre uma medida que já foi ou poderá vir a ser adotada pelos poderes constituídos, no plano local ou nacional (FERNANDES, 2000).
} 
comercialização de arma de fogo e munição em todo o território nacional, salvo para as entidades previstas no art. $6^{\circ}$ desta Lei".

Para a realização desse referendo, considerou-se a gravidade da questão, evidenciando-se a necessidade de se submeter à consulta popular a decisão sobre o comércio de armas de fogo e munição. A decisão pela realização desse referendo foi promulgada pelo Senado Federal em 7 de julho de 2005 pelo decreto legislativo $\mathrm{n}^{\circ} 780$. $\mathrm{Na}$ ocasião, os eleitores puderam optar pela resposta "sim" ou "não", pelo voto em branco ou pelo voto nulo. O resultado final foi de 59.109.265 votos respondendo "não" $(63,94 \%)$, enquanto 33.333.045 votaram pelo "sim" (36,06\%). Logo, o artigo que proibia a comercialização de arma de fogo e munição não foi permitido na Lei do Desarmamento naquela ocasião, já que, havendo vencido a opção não, a população entendera que não deveria ser proibida a venda de armas e munição.

Essa temática, além de atual, era bastante polêmica e, efetivamente, dividiu opiniões no grupo de alunos envolvidos no projeto e em toda a comunidade escolar, local e global, já que todo o país e os meios de comunicação estavam focados nessa discussão. A repercussão de um tema dessa natureza na mídia e nas redes sociais favorece o trabalho com a leitura (e com a escrita também) na sala de aula, pois a circulação de textos com a discussão da problemática se amplia de forma que até a mobilização de recursos pelo professor ocorre mais facilmente.

Durante a realização do projeto, os alunos sugeriram a organização de um debate regrado e a leitura foi o ponto de partida para esta e as demais ações do projeto. A produção do debate sedimentou a construção dos seus pontos de vista; formaram-se grupos favoráveis e outros desfavoráveis ao desarmamento, uma atitude indipensável para o pluralismo do debate. A partir do posicionamento assumido, muitos textos de diferentes gêneros discursivos foram lidos em sala de aula, na biblioteca e no laboratório de informática. Essa variedade de ambientes de leitura foi importante para quebrar a monotonia das práticas escolarizadas de leitura, desterritorializando as práticas de letramento e dinamizando o processo de ensino.

Depois do debate, aberto à comunidade escolar, à comunidade do entorno e realizado na quadra de esportes, para garantir a participação de um público no evento, os alunos sugeriram a realização de uma pesquisa de opinião. Em sessão reflexiva, foi deliberado incluir não só os alunos, mas também professores e funcionários e, portanto, a pesquisa foi realizada com os diversos segmentos da comunidade escolar. O resultado 
apontou para a vitória do SIM, isto é, para a posição favorável ao desarmamento, embora com uma diferença muito pequena em relação ao NÃO. Também foi sugerida uma pesquisa online no site do colégio, no qual familiares, amigos e os próprios alunos pudessem votar.

Ao longo do processo, o laboratório de informática da escola tornou-se um importante espaço para diversificar as práticas de leitura, proporcionando ao grupo a organização de um fórum online. Nesse laboratório, foram realizadas oficinas de letramento, para que os alunos tivessem acesso não só ao que circulava nos jornais locais, mas também nos jornais de circulação nacional como A Folha de São Paulo, $O$ Globo etc.

\section{Oficinas de letramento: foco na leitura}

Pedagogicamente, compreendemos oficina de letramento como um dispositivo didático em que se tem por objetivo desenvolver atividades práticas que envolvem usos da escrita. Diz respeito ao modo de organização das ações de linguagem mediadas por gêneros discursivos, materializados em textos orais e escritos, que dão suporte a práticas de leitura, escrita e fala. Na planificação desse tipo de oficina ou de qualquer unidade didática, a determinação do objetivo é central. A primeira questão de ordem didática é ter clareza sobre os motivos da seleção do gênero, para depois refletir sobre como abordar esse gênero na sala de aula.

As oficinas com foco na leitura demandam que o professor considere: a mobilização de recursos e artefatos necessários para realizar a diversidade de práticas de leitura (silenciosa, oral, compartilhada, orientada - quando fazíamos questões norteadoras para facilitar a compreensão -, releitura, dramatização, declamação etc.); o uso de diferentes recursos midiáticos (CD, DVD, filmes, jogos digitais, música, aparelho de som, computador, tablet, livros impressos e digitais, audiolivros, ferramentas de apresentação como prezi, slides etc.); o trabalho com as diferentes linguagens (gráficas, verbal, não verbal, musical, gestual etc.) e os diferentes gêneros discursivos materializados em textos (charges, artigos de opinião, reportagens, notícias, histórias em quadrinhos, contos, poemas, romances, fábulas, crônicas, minicontos, folhetos de cordel, peças de teatro etc.). 
Considerando a multiplicidade de linguagens, práticas, tecnologias, recursos e artefatos utilizados, uma oficina de leitura contribui para uma recepção e compreen são mais crítica dos textos ou de outros artefatos culturais trabalhados. Além disso, esse tipo de oficina, quando desenvolvida nessa perspectiva, imprime um caráter inovador às práticas de letramento desenvolvidas na escola, visto que oportuniza o acesso às tecnologias digitais, conforme propõem as orientações da Base Nacional Comum Curricular (BNCC) e as Diretrizes Curriculares para o Ensino Médio (DCNEM).

Em face das crescentes exigências do mundo contemporâneo, as atividades de leitura e escrita na escola não se restringem ao texto verbal escrito, ainda que este lhes seja imprescindível. É indispensável que a imagem seja melhor explorada no contexto escolar, posto que a internet exerce uma grande atração sobre os estudantes. Eles gostam de navegar, de descobrir novos endereços, de se comunicar com outros colegas. Além disso, o trabalho com o texto em uma perspectiva multissemiótica, em que se misturam cores, movimentos, sons e imagens desperta um maior interesse dos alunos, motivando-os para a leitura. Tendo em vista a relevância da charge para a formação do ponto de vista dos alunos sobre o assunto em discussão, sugerimos o acesso a outros sites, um deles especializado em charges animadas, onde o gênero é trabalhado com todos esses recursos. Os alunos passaram a se interessar ainda mais pela charge.

No projeto aqui analisado, a escolha do gênero charge se deu pelo importante papel que ele pode cumprir na formação leitora crítica, visto que o trabalho com esse gênero favorece a construção de pontos de vista e de visões de mundo sobre a realidade econômica, social e política dos educandos. Nesse sentido, os alunos (leitores) podem refletir sobre diferentes pontos de vista e construírem suas próprias opiniões sobre um determinado tema, contribuindo, assim, para o desenvolvimento de competências relativas ao domínio dos textos argumentativos, essenciais ao exercício da cidadania crítica, do protagonismo e do ativismo social e político dos alunos.

Uma das maiores dificuldades de compreensão da charge, o estabelecimento de relações entre a ironia ou humor no texto e a crítica do mundo social em um determinado tempo e espaço, fica notadamente diminuída porque o leitor tem acesso ao conhecimento do mundo necessário para a interpretação devido à contextualização constante do acontecimento, como polêmico tema de discussão e leitura diária na aula, na rua, nos meios jornalísticos. 
As oficinas de letramento assumem um caráter prático e mais dinâmico, pois os alunos escolhem o que ler. Leitores proficientes fazem escolhas por estarem inseridos em um universo textual amplo e diversificado. Nessas oficinas, os alunos praticam diferentes modos de leitura, leem diferentes textos de seu interesse, de diferentes gêneros discursivos e em diferentes suportes, imprimindo-lhes um caráter de prática social.

Há, na oficina em questão, uma etapa da exposição, posterior às práticas de leitura, na qual o professor explica aos alunos as marcas e especificidades do gênero charge, trata do tipo textual predominante em sua composição - o argumentativo; orienta o aluno à apreensão do ponto de vista defendido pelo chargista, identificando se este se mostra favorável ou desfavorável ao desarmamento. Mas a exposição dialogada também é importante, para que o professor trabalhe sistematicamente os conteúdos planejados: aspectos composicionais, multissemióticos e enunciativo-discursivos da charge; diferenças entre charge, cartum, caricatura e tirinha; práticas diversas de leitura segundo os objetivos, características do gênero: ironia, intertextualidade, inferência de implícitos, etc.

Tudo isso favorece a formação leitora dos alunos e dinamiza o processo de ensino, motivando e estimulando o engajamento deles nas práticas sociais de leitura. Contribui para a aprendizagem de conteúdos de diversas áreas e a produção de conhecimentos em uma perspectiva interdisciplinar (KLEIMAN; MORAES, 1999). Diversificar práticas de leitura torna-se importante, porque favorece a compreensão dos fatos sociais e da realidade, para que o educando possa saber se posicionar no mundo da escola e no mundo social mais amplo.

Os procedimentos utilizados impuseram certa dinamicidade à ação pedagógica e motivaram a participação nas atividades. A motivação dos alunos pôde ser observada através do interesse manifestado pela leitura dos vários textos que circularam na sala. Isso ratifica o que afirma Bazerman (2006, p. 48): "ler é profundamente interessante se os alunos vêem uma conexão entre o texto e alguma tarefa em que estão engajados ou entre o texto e algum assunto sobre o qual estão pensando no momento". Conforme podemos ver no depoimento ${ }^{9}$ de uma colaboradora do projeto, aprender a ler nas oficinas de projetos de letramento ajuda na formação crítica dos educandos:

\footnotetext{
${ }^{9}$ Os depoimentos foram gerados por ocasião de uma sessão reflexiva destinada à avaliação e reflexão sobre as ações desenvolvidas no projeto de letramento.
} 
com a leitura, a gente fica mais preparada para o debate das ideias, aprende a argumentar embasada em fatos, dados, números, estatísticas etc. Aprende a questionar e até a dialogar de igual para igual com as pessoas sobre o tema estudado. Quanto mais a gente lê mais percebe como são as coisas na realidade, parece que a leitura tira uma venda dos olhos da gente. Nas oficinas, a gente não aprende só uma coisa, uma só matéria, aprende várias (Filosofia, Sociologia, Português, Artes, Geografia, Matemática), pesquisando o número de mortes para fazer um mapa da violência no país inteiro, fazer gráficos e apresentar nas oficinas [...] (Lorena - Turma B).

Para a estudante, as práticas contribuem para expandir as visões de mundo, formar opinião e preparar para "dialogar de igual para igual", pois aprendeu a perceber "como são as coisas na realidade". O caráter interdisciplinar das oficinas, segundo declara a aluna: "Nas oficinas, a gente não aprende só uma coisa, uma só matéria, aprende várias (Filosofia, Sociologia, Português, Artes, Geografia, Matemática)", favorecido pela perspectiva do letramento, promove uma aprendizagem significativa dos conteúdos o que, em um tempo em que é difícil motivar o aluno no EM, pode fazer uma grande diferença.

Esse modo de abordar a leitura em sala de aula rompe com uma forma tradicional de ensino, quando dá vez, voz e autonomia aos alunos para lerem coisas do seu interesse, diferentemente da prática tradicional de ensino de leitura, que

não propicia a interação entre professor e aluno. Em vez de um discurso que é construído conjuntamente por professores e alunos, temos primeiro uma leitura silenciosa ou em voz alta do texto, e depois, uma série de pontos a serem discutidos, por meio de perguntas sobre o texto, que não leva em conta se o aluno de fato o compreendeu. Trata-se, na maioria dos casos, de um monólogo do professor para os alunos escutarem. Nesse monólogo o professor tipicamente transmite para os alunos uma versão, que passa ser a versão autorizada do texto. (KLEIMAN, 2000, p. 24).

A função do professor é levar o aluno mais longe no processo de aprendizagem da leitura, ampliando suas chances de aprender. Isso ocorre quando este torna-se capaz de ler além das entrelinhas, de compreender, por exemplo, que em torno de uma charge há outros textos fundantes que circulam geralmente no mesmo dia de circulação da charge, pois esse gênero está em diálogo com outros, tais como notícias, editoriais, repostagens, cartas do leitor etc. 
Após a oficina de leitura, os alunos se envolveram em um turbilhão de ideias e demonstravam familiaridade com o tema do referendo popular e com os gêneros discursivos lidos e produzidos no projeto. Surgiram ideias para novas atividades: uma pesquisa de opinião, uma carta aberta a ser entregue em uma mobilização na rua, com faixas, a fim de formar a opinião da população.

A leitura foi o detonador dessas atividades, assim como o foi para a produção de uma charge, ainda que, considerando a singularidade do gênero e os pressupostos que embasam o trabalho em torno dos usos sociais da leitura e da escrita situadamente, a leitura de charges, na oficina, não tinha por objetivo final propor aos alunos a produção de textos do gênero. No entanto, a vivência com esse gênero despertou numa aluna o desejo para criar textos como os lidos, e produziu a charge a seguir:

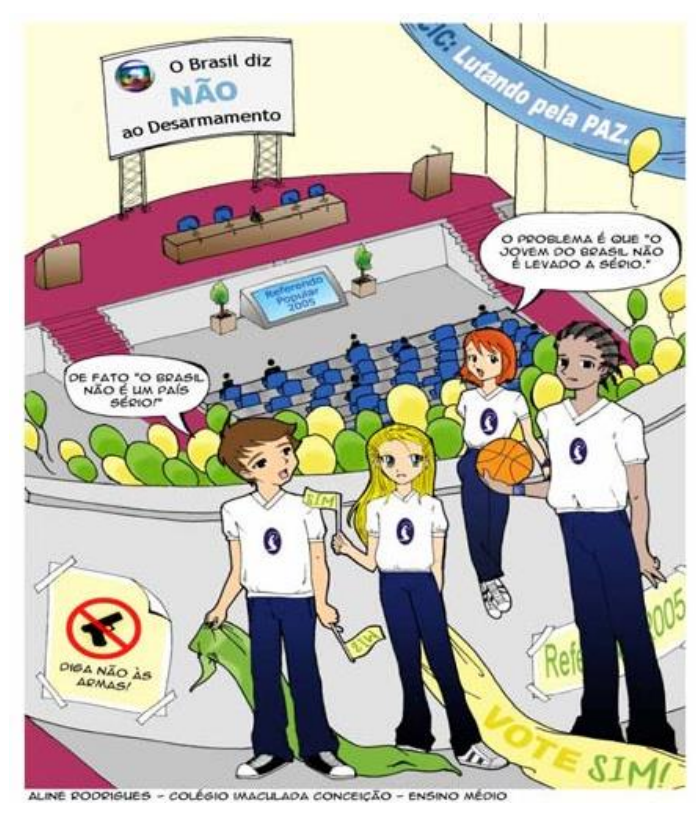

Não se justifica propor aos alunos a produção de charges em série, primeiro porque nem todos os alunos têm interese no trabalho de criação artística; segundo porque há gêneros que podem servir mais aos propósitos da formação leitora se não há um propósito comunicativo definido que justifique sua produção. Não faz sentido ensinar a escrever um editorial, uma reportagem, uma notícia se não temos uma razão para isso, como a produção de um jornal escolar, como ilustra o trabalho de Cunha (2010). Esses gêneros tornam-se importantes para as práticas de produção quando têm uma função social definida e não há neessidade de descolá-los da prática social. 
Após o resultado do referendo popular, achávamos que o projeto estivesse concluído, mas foi-nos apresentada a charge supracitada, materializada em um texto bastante representativo do trabalho realizado com esse gênero em sala de aula. Por sugestão de alguns o texto foi publicado no site e no jornal impresso do colégio, pois representaria o sentimento do grupo em relação ao resultado do referendo popular, isto é, à perda da frente que defendia a proibição da venda de armas de fogo e munição no país. Observando as expressões das personagens e o próprio cenário do texto (cartaz descolando, faixas no chão, bandeira abaixada etc.) podemos inferir o estado de ânimo diante do desfecho do referendo popular.

Podemos observar, do ponto de vista formal, que o texto apresenta-se com as marcas que caracterizam o gênero charge: critica, de forma humorística, um fato político situado, assumindo um ponto de vista desfavorável ao resultado da votação. O texto põe em relevo a capacidade de argumentação da aluna, que articula tanto elementos caracterizadores da estrutura formal, quanto elementos discursivos: conversa com vozes alheias (por ex., "o Brasil não é im país sério”, frase atribuída a diversas personalidades) para realizar uma leitura crítica dos fatos sociais e políticos, a serviço de seu potencial criativo e de expressão pessoal.

Nesta experiência, a leitura serve de ponte para transpor os alunos, quando se tornam leitores proficientes, a processos altamente criativos. Essa é uma das funções da escrita pouco desenvolvida nas escolas e menos ainda nas escolas públicas onde estão a maioria dos alunos das classes sociais menos favorecidas, que, muitas vezes, aprendem apenas funções mais instrumentais da escrita.

Freire e Macedo (1990) discutem a importância de desenvolver a subjetividade dos educandos, pois a escola é um espaço social onde se desenvolvem aspectos subjetivos dos indivíduos, dentre eles a criatividade. Para os autores, na educação, historicamente, a criatividade dos alunos é reprimida. Contudo, "a criatividade precisa ser estimulada, não só no nível da individualidade do aluno, mas também no nível de sua individualidade num contexto social" (FREIRE; MACEDO, 1990, p. 39). Quando isso acontece, o aluno se sente encorajado e ousa dar expressão ao seu talento.

A aluna que reagiu tão positivamente às práticas pedagógicas desenvolvidas em sala de aula valoriza o trabalho realizado: 
Trabalhamos muito durante o ano. E trabalhamos pra valer! Lemos charges, leis, artigos de opinião, editorial, notícias, reportagens, entrevistas, documentários e até poemas e músicas. Tudo isso para produzir enquete, debate, carta aberta, faixas (o texto), charge, mural, e-mail etc.. Que ano produtivo! Hoje sou PRODUTORA e não apenas leitora de charges. Foi realmente um momento de orgulho ver o meu trabalho circular na sociedade, na mobilização feita na rua, formando a opinião de outras pessoas (Lorena - Turma B).

O ensino torna-se mais produtivo, pois a oficina de letramento contribui para tratar de especificidades da leitura de charges: formar uma opinião, ensinar a argumentar. "Assumir uma posição" permite a realização de muitas atividades sem perder de vista o papel central dessa prática no processo, conforme ela continua:

[...] estou mais consciente agora, para que serve a leitura porque o projeto despertou em mim um olhar mais crítico para os textos que leio. Aprendi a não ficar em cima do muro, porque para argumentar é preciso assumir uma posição (Lorena - Turma B).

Aprendendo a usar sua língua de forma criativa, mediados pelos gêneros discursivos assumidos como instrumentos para subsidiar o ativismo social e a sua agência cívica, os alunos entendem melhor os usos cotidianos e o poder da escrita. A ação dos alunos nesse projeto coloca-os efetivamente na condição de agentes, revelando que a leitura crítica os prepara para uma atuação comprometida com o seu contexto.

\section{Algumas conclusões}

Neste artigo, analisamos uma oficina com o foco na leitura de charges, discutimos o papel dos estudantes-agentes e a necessidade de ressignificação das práticas de leitura escolarizadas. A análise crítico-reflexiva sugere que os projetos de letramento contribuem para a formação de leitores críticos e produtores de textos multissemióticos de diferentes gêneros, à medida que oportunizam trazer para a sala de aula práticas sócio-históricas reais por eles vivenciadas. Evidencia-se a necessidade de se repensar as práticas de letramento na escola, considerando os sujeitos para além da sua condição escolar e levando em conta suas necessidades de participação social pelos usos da linguagem. 
As vivências e a reflexão sobre as práticas de letramento nos depoimentos ressaltam a relevância do trabalho com projetos de letramento, uma vez que a aprendizagem se dá no processo de produzir, pesquisar, criar, descobrir, compreender e (re)construir conhecimentos. Os projetos abrem possibilidades para que os alunos leiam e aprendam para a realização de atividades relevantes para seus percursos escolares e não escolares.

As oficinas de letramento cumprem um importante papel no trabalho com as especificidades das práticas de leitura. Pelo seu caráter pedagógico, dinâmico, prático, dialógico e participativo, o trabalho com oficinas contribui para motivar os alunos para a aprendizagem da leitura e a ampliação de seus letramentos, preparando-os para o exercício da cidadania critica e participativa ao enraizá-los no seu contexto sóciohistórico.

Experiências como a que ora analisamos implicam uma postura crítica, reflexiva e engajada, no sentido de formar sujeitos-agentes, construtores de sua cidadania. Isso exige bastante de professores, alunos e também da própria escola, a qual muitas vezes não se dispõe a relativizar o seu poder de decisão sobre aquilo que se faz na sala de aula nem tampouco fora dos seus muros.

Um trabalho dessa natureza demanda que se altere a quietude da escola, incentivando ações que ali se desenvolvem em oficinas, cujo caráter mais prático contribui para movimentar os espaços de aprendizagem, dinamizar as práticas pedagógicas e motivar o aluno para ler mais e melhor.

\section{Referências bibliográficas}

ANASTÁCIO, J. M.; GARCIA, R. Projetos de letramento: estratégias de potencialização ao ensino da escrita, Cespuc, Belo Horizonte - n. 25 - 2014, p. 134150 .

ASSIS, J. M. Machado de. Correspondência. Rio de Janeiro: W. M. Jackson, 1937.

BAKHTIN, M. Questões de literatura e de estética: a teoria do romance. São Paulo: Hucitec 1990.

BAKHTIN, M. Estética da criação verbal. 3. ed. São Paulo: Martins Fontes, 1999.

BARTON, D.; HAMILTON, M.; IVANIC, R. (Orgs.). Situated literacies. London: Routledge, 2000.p. $01-06$. 
BAZERMAN, C. Gêneros textuais, tipificação e interação. São Paulo: Cortez, 2005.

BAZERMAN, C. Gênero, agência e escrita. São Paulo: Cortez, 2006.

CORREIA, K. Projetos de Letramento no Ensino Médio: novas perspectivas e desafios, Educação \& Realidade, v.41, n.1. Porto Alegre, jan./mar. 2016.

CUNHA, R. Jornal escolar: raios de ações, rede de significações. Reconfiguração do ensino de língua materna e dinamização da formação continuada do professor. Tese (Doutorado em Linguística Aplicada). Campinas: Instituto de Estudos da Linguagem. Universidade Estadual de Campinas, 2010.

DIAS, D. M. Projeto de letramento na escola: possibilidade para ampliar a participação social dos alunos por meio de práticas de escrita. Dissertação. 2016. Universidade Federal de Minas Gerais. Disponível em: https://sites.google.com/site/estudosdeletramento/projeto-de-letramento.

FREIRE, B. V. R. O projeto de letramento como alternativa para uma aprendizagem significativa no primeiro ano do ensino fundamental. Dissertação.. Universidade Federal de São Carlos. 2017.

FREIRE, P. Educação como prática da liberdade. Rio de Janeiro: Paz e Terra, 1971.

FREIRE, P. Pedagogia do oprimido. Petrópolis/RJ: Vozes, 1978.

FREIRE, P. Pedagogia da indignação: cartas pedagógicas e outros escritos. São Paulo: Paz e Terra, 2000.

FREIRE, P.; MACEDO, D. Alfabetização: leitura da palavra leitura do mundo. Rio de Janeiro: Paz e Terra, 1990.

KLEIMAN, A. B. (Org.). Os significados do letramento: uma perspectiva sobre a prática social da escrita. Campinas/SP: Mercado de Letras, 1995.

KLEIMAN, A. B.. O processo de aculturação pela escrita: ensino de forma ou aprendizagem da função? In: KLEIMAN, A. B.; SIGNORINI, I. O ensino e a formação do professor: alfabetização de jovens e adultos. Porto Alegre: Artes Médicas do Sul, 2000.

KLEIMAN, A. B.. Processos identitários na formação profissional - o professor como agente de letramento. In: CORRÊA, M. L. G.; BOCH, F. (Orgs.). Ensino de língua: representação e letramento. Campinas, SP: Mercado de Letras, 2006.

KLEIMAN, Angela B. Projetos de letramento na educação infantil. Revista Caminhos em Linguística Aplicada, Volume 1, Número 1, p. 1-10. 2009. Disponível em: www.unitau.br/caminhosla

KLEIMAN, A. B.; MORAES, S. E. Leitura e Interdisciplinaridade. Tecendo redes nos projetos da escola. Campinas, S.P.: Mercado de Letras, 1999.

KLEIMAN, A. B.; CENICEROS, R. C.; TINOCO, G. A. Projetos de letramento no ensino médio. In: BUNZEN, C.; MENDONÇA, M. (org.) Múltiplas linguagens para o ensino médio. São Paulo: Parábola Editorial, 2013.

MILLER, C. R. Estudos sobre: gênero textual, agência e tecnologia. Recife: Ed. Universitária da UFPE, 2009. 
OLIVEIRA, M. S. Projetos: uma prática de letramento no cotidiano do professor de língua materna. In: OLIVEIRA, M. S.; KLEIMAN, A. B.(org.) Letramentos múltiplos: agentes, práticas e representações. Natal: EDUFRN, 2008.

OLIVEIRA, M. S. O que é, como se faz e o que significa trabalhar com projeto de letramento. In: SATO, D. T. B.; BATISTA JÚNIOR, J. R. L.; SANTOS, R. C. R. Ler, escrever, agir e transformar: uma introdução aos novos estudos do letramento. Recife: Pipa Comunicação, 2016, p.279-303.

SANTOS, I. B. A. Projetos de letramento: ressignificação da prática docente. In: OLIVEIRA, M. S.; KLEIMAN, A. B. (org.) Letramentos múltiplos: práticas e representações. Natal/RN: EDUFRN, 2008.

OLIVEIRA, M. S. Letramento cívico na EJA: o trabalho com os gêneros discursivos em projetos de letramento. Fórum Linguístico, v. 9, n. 4, p. 283-303, out./dez. 2012. Disponível em: http://dx.doi.org/10.5007/1984-8412.2012v9n4p283. Acesso em: 02.05.2019.

SANTOS, I. B. A.; OLIVEIRA, M. S. Políticas públicas na educação de jovens e adultos: projetos de letramento, participação e mudança social. Revista EJA em debate, v. 1, n. 1, 2012, p. 39-56.

SANTOS MARQUES, I. B. A; KLEIMAN, A. B. Educação profissional para além da formação técnica e tecnológica. Revista EJA em debate, v. 6, n. 9, 2017. Disponível em: https://periodicos.ifsc.edu.br/index.php/EJA/article/view/2294/ART. Acesso em 02/05/2019.

SANTOS MARQUES, I. B. A. O ensino de escrita na perspectiva do letramento e do empoderamento para a participação e mudança social. In: SATO, D. T. B.; BATISTA JÚNIOR, J. R. L.; SANTOS, R. C. R. Ler, escrever, agir e transformar: uma introdução aos novos estudos do letramento. Recife: Pipa Comunicação, 2016, p. 179-205.

SANTOS MARQUES, I. B. A. A formação de professores de língua portuguesa: projetos de letramento, agência e empoderamento. In: KLEIMAN, A. B.; ASSIS, J. A. Significados e ressignificações do letramento: desdobramentos de uma perspectiva sociocultural sobre a escrita. Campinas, SP: Mercado de Letras, 2016a, p. 111-142.

SCRIBNER, S.; COLE, M. The psychology of literacy. Cambridge, MA: Harvard University Press, 1981.

SOUZA, F. F. B. $O$ ensino de língua portuguesa e os projetos de letramento: uma proposta de atividades com foco na questão alimentar a partir do gênero anúncio de campanha comunitária. Dissertação. Universidade Federal de Paraíba. 2017

TINOCO, G. A. Projetos de letramento: ação e formação de professores de língua materna. Campinas/SP. Tese (Doutorado em Linguística Aplicada) - Universidade Estadual de Campinas: Unicamp. 2008.

VOLOCHINOV, V. N. Marxismo e filosofia da linguagem. São Paulo: Hucitec, 2000 . 